Gut and Liver, Vol. 10, No. 4, July 2016, pp. 497-498

\title{
Combination of Pegylated Interferon and Nucleos(t)ide Therapy: Toward a Cure of Hepatitis B Virus Infection?
}

\author{
Eun Ju Cho, Jeong-Hoon Lee, and Jung-Hwan Yoon \\ Department of Internal Medicine and Liver Research Institute, Seoul National University College of Medicine, Seoul, Korea
}

See "Potential Efficacy of Pegylated Interferon- $\alpha$ and a Nucleos(t)ide Analogue as Combination Therapy for HBeAg-Positive Chronic Hepatitis B" by Chung-Il Wi, et al. on page 611, Vol. 10. No. 4, 2016

Current treatments for chronic hepatitis B virus (HBV) infection based on nucleos(t)ide analogues (NUCs) can efficiently suppress viral replication and improve patient outcomes. However, as they do not eradicate intrahepatic covalently closed circular DNA (cccDNA), long-term therapies are required to sustain antiviral effects. ${ }^{1}$ In contrast, interferon has different modes of action including immunomodulation and degradation of cccDNA via activation of APOBEC3A. However, the antiviral effect of interferon is moderate, and it is successful in only a minority of patients. ${ }^{2}$ To solve the unmet need for a cure of HBV infection, combination therapies suppressing both HBV replication (using NUCs) and cccDNA transcription (using pegylated interferon $\alpha$ [Peg-IFN- $\alpha]$ ) have been studied.

In previous studies comparing de novo combination of PegIFN- $\alpha$ and lamivudine treatment with each treatment alone in HBV e antigen (HBeAg)-positive chronic hepatitis B patients, combination therapy induced higher on-treatment HBV suppression than either alone; however, there was no clear benefit over Peg-IFN- $\alpha$ monotherapy in alanine aminotransferase (ALT) normalization, HBeAg seroconversion, and sustained offtreatment response., Administration of low-potency NUC and early treatment discontinuation before achieving a desirable response might have contributed to the failure of combination treatment. Thus, recent studies have investigated the effects of various combination regimens of more potent NUC (i.e., entecavir or tenofovir) and Peg-IFN- $\alpha$ for extended durations. Wi et $a .^{5}$ explored the efficacy of Peg-IFN- $\alpha$ plus either entecavir or tenofovir in HBeAg-positive chronic hepatitis B patients. Ten patients were treated with Peg-IFN- $\alpha$ for 48 weeks and either entecavir or tenofovir was added 8 weeks after the initiation of Peg-IFN- $\alpha$ and continued for $>6$ months after achieving
HBeAg-seroconversion. Thus, there was a 40-week overlap of Peg-IFN- $\alpha$ and a NUC. This strategy may theoretically intensify host immune stimulation by Peg-IFN- $\alpha$ by avoiding simultaneous NUC therapy-induced suppression of viral antigen presentation. ${ }^{6}$ Of 10 patients who received combination treatment, eight developed HBeAg loss, including four with off-treatment $\mathrm{HBeAg}$ seroconversion and one with HBsAg seroconversion. Although this is a small case series study with modest follow-up period, this favorable treatment response supports further investigation of combination therapy. Recently, a study on de novo tenofovir and Peg-IFN- $\alpha$ combination treatment reported that 48-week concomitant treatment with tenofovir and Peg-IFN- $\alpha$ led to higher rates of HBsAg loss compared with Peg-IFN- $\alpha$ monotherapy. ${ }^{7}$ However, the rates of HBeAg seroconversion, undetectable serum HBV DNA, and the proportion of patients receiving tenofovir rescue treatment were not different between the two groups.

Theoretically, potent NUC-induced viral load decrease may restore an impaired adaptive immune response, and enhance the immunomodulatory effects of Peg-IFN- $\alpha$. Furthermore, PegIFN- $\alpha$ consolidation may also decrease reactivation of $\mathrm{HBV}$ following discontinuation of NUC therapy and reduce treatment duration. Several recent trials have investigated the efficacy of starting with NUCs followed by Peg-IFN- $\alpha$ therapy. In the NEED study evaluating the efficacy of 48-week Peg-IFN- $\alpha$ therapy after 4-week pretreatment with adefovir or entecavir, short-term NUC pretreatment failed to increase off-treatment HBeAg seroconversion rates beyond those achieved by PegIFN- $\alpha$ alone. ${ }^{8}$ This result suggests that 4 -week pretreatment with NUC is too short to influence the outcome. On the other hand, the OSST trial investigated the efficacy of switching to a finite

\footnotetext{
Correspondence to: Jung-Hwan Yoon

Department of Internal Medicine and Liver Research Institute, Seoul National University College of Medicine, 101 Daehak-ro, Jongno-gu, Seoul 110-744, Korea

Tel: +82-2-2072-2228, Fax: +82-2-743-6701, E-mail: yoonjh@snu.ac.kr pISSN 1976-2283 eISSN 2005-1212 http://dx.doi.org/10.5009/gnl15307

@ This is an Open Access article distributed under the terms of the Creative Commons Attribution Non-Commercial License (http://creativecommons.org/licenses/by-nc/4.0) which permits unrestricted non-commercial use, distribution, and reproduction in any medium, provided the original work is properly cited.
} 
course of 48-week Peg-IFN- $\alpha$ in patients reaching virological suppression with entecavir. ${ }^{9}$ Serological response rates, including $\mathrm{HBeAg}$ seroconversion and HBsAg loss, were significantly higher in the group switching to Peg-IFN- $\alpha$ than in the entecavir maintenance group; however, HBV DNA suppression and ALT normalization were comparable between the two groups. In addition, safety problems including virological breakthrough and adverse events were reported only in the Peg-IFN- $\alpha$ group. The ARES study, investigating Peg-IFN- $\alpha$ add-on strategy, showed that 24 weeks of Peg-IFN- $\alpha$ add-on preceded by $24-$ week entecavir treatment significantly improved on-treatment declines in HBsAg, HBeAg, and HBV DNA levels, as well as offtreatment HBeAg seroconversion at week 96, compared with entecavir monotherapy. ${ }^{10}$ However, the rates of off-treatment HBsAg seroconversion, HBV DNA <200 IU/mL, and ALT normalization were similar. In addition, Peg-IFN- $\alpha$ monotherapy was not studied. With regard to the value of Peg-IFN- $\alpha$ add-on to entecavir, the results are inconclusive.

Collectively, there has been no concrete evidence that the combination of Peg-IFN- $\alpha$ and NUCs can improve off-treatment sustained response rate, and current international guidelines do not recommend combination treatment for chronic hepatitis B. Further large prospective trials with analyses of the immune responses are warranted to clearly characterize the efficacy and safety of combination treatment in the shortening of the duration of NUC therapy. In addition, long-term safety and costeffectiveness issues related to NUCs in patients with advanced liver disease who require indefinite NUC treatment should be addressed in future studies.

\section{CONFLICTS OF INTEREST}

No potential conflict of interest relevant to this article was reported.

\section{REFERENCES}

1. Shim JJ. Long-term suppression of viral replication in chronic hepatitis B: outcomes and future directions. Gut Liver 2015;9:265266

2. Kwon JH, Kim YS, Kim SG, et al. The efficacy and safety of peginterferon-alpha-2a in Korean patients with chronic hepatitis B: a multicenter study conducted in a real clinical setting. Gut Liver 2013;7:197-205.

3. Lau GK, Piratvisuth T, Luo KX, et al. Peginterferon Alfa-2a, lamivudine, and the combination for $\mathrm{HBeAg}$-positive chronic hepatitis B. N Engl J Med 2005;352:2682-2695.

4. Janssen HL, van Zonneveld M, Senturk H, et al. Pegylated interferon alfa-2b alone or in combination with lamivudine for HBeAg-positive chronic hepatitis B: a randomised trial. Lancet 2005;365:123-129.

5. Wi CI, Kim WR, Gross JB, Stadheim LM, Poterucha JJ. Potential efficacy of pegylated interferon-alfa and a nucleos(t)ide analogue as combination therapy for HBeAg-positive chronic hepatitis B. Gut Liver 2016;10:611-616.

6. Thimme R, Dandri M. Dissecting the divergent effects of interferon-alpha on immune cells: time to rethink combination therapy in chronic hepatitis B? J Hepatol 2013;58:205-209.

7. Marcellin P, Ahn SH, Ma X, et al. HBsAg loss with tenofovir disoproxil fumarate (TDF) plus peginterferon alfa-2a (PEG) in chronic hepatitis $\mathrm{B}(\mathrm{CHB})$ : results of a global randomized controlled trial. Hepatology 2014;60(Suppl 1):294A-295A.

8. Su WW, Hsu CW, Lee CM, et al. 0113 Combination therapy with peginterferon alfa-2a and a nucleos(t)ide analogue for $\mathrm{HBeAg}$ positive chronic hepatitis B patients: results of a large, randomised, multicentre, double-blind, placebo-controlled study. J Hepatol 2014;60(1 Suppl):S47.

9. Ning Q, Han M, Sun Y, et al. Switching from entecavir to PegIFN alfa-2a in patients with HBeAg-positive chronic hepatitis B: a randomised open-label trial (OSST trial). J Hepatol 2014;61:777-784.

10. Brouwer WP, Xie Q, Sonneveld MJ, et al. Adding pegylated interferon to entecavir for hepatitis B e antigen-positive chronic hepatitis B: a multicenter randomized trial (ARES study). Hepatology 2015;61:1512-1522. 